\title{
PELAKSANAAN PERJANJIAN KREDIT BANK DENGAN SURAT KUASA MEMBEBANKAN HAK TANGGUNGAN (SKMHT) DI KABUPATEN TABANAN*
}

Oleh:

I Gusti Nyoman Kusuma Primayadnya* Ida Bagus Erwin Ranawijaya**

Program Kekhususan Hukum Bisnis Fakultas Hukum Universitas Udayana

\begin{abstract}
ABSTRAK
Penelitian ini membahas mengenai pembebanan hak tanggungan untuk tanah-tanah yang sudah terdaftar yang kemudian oleh kantor pertanahan dikeluarkan sertipikat Hak Tanggungan. pembebanan hak tanggungan untuk tanah-tanah yang sudah terdaftar didahului dengan pembuatan APHT oleh PPAT, yang kemudian oleh kantor pertanahan dikeluarkan sertipikat Hak Tanggungan. Untuk tanah-tanah yang belum terdaftar dan tanahtanah yang berada diluar wilayah kerja kreditor, pembebanan Hak Tanggungannya adalah dalam bentuk SKMHT yang juga dibuat oleh Notaris/PPAT. Dalam praktek, meskipun sertipikatnya dikantor BPN telah lewat masa 3 bulan, tidak segera dibuat APHT. Oleh debitur dengan persetujuan kreditor, hanya dibuat SKMHT yang baru sebagai pengganti SKMHT yang telah berakhir. Akibat hukum dari terlaksa nya SKMHT dalam perjanjian kredit Bank apa bila melebihi jangka waktu yg di tentukan maka SKMHT tersebut batal demi hukum. Akibat nya kreditur tidak memiliki hak untuk mngesekkusi jaminan yang di berikan debitur bila melakukan wanprestasi, senhingga menimbulkan kerugian bagi kreditur
\end{abstract}

Kata Kunci: Perjanjian Kredit Bank, SKMHT, Kabupaten Tabanan.

*) Makalah ini merupakan ringkasan skripsi

*) I Gusti Nyoman Kusuma Primayadnya adalah Mahasiswa Fakultas Hukum Universitas Udayana

**) Desak Putu Dewi Kasih adalah Dosen Pengajar Hukum Perdata Fakultas Hukum Universitas Udayana, sebagai penulis II

***) Ida Bagus Erwin Ranawijaya adalah Dosen Pengajar Hukum Internasional Fakultas Hukum Universitas Udayana, sebagai penulis II 


\begin{abstract}
This research explain about the imposition of mortgages for lands that have been registered is preceded by the making of the APHT by the PPAT, which is then issued by the land office certificate of Underwriting Rights. The imposition of mortgages for lands that have been registered is preceded by the making of the APHT by the PPAT, which is then issued by the land office certificate of Underwriting Rights. For lands that have not been registered and lands that are outside the work area of the creditor, the imposition of Underwriting Rights is in the form of SKMHT which is also made by a Notary / PPAT. In practice, even though the certificate at the BPN office has passed the 3 month period, the APHT is not immediately made. By the debtor with the approval of the creditor, only the new SKMHT is made in lieu of the SKMHT that has expired. The obstacles that arise when making and increasing SKMHT to APHT, namely the cost of increasing SKMHT to APHT and a short period of time becomes the next problem. This is because the loan agreement period is longer. Efforts made in overcoming these obstacles, namely by renewing the SKMHT which has expired.The legal consequences of the SKMHT enforced in the Bank's credit agreement if it exceeds the stipulated period, the SKMHT is null and void by law. As a result, the creditor does not have the right to contract the collateral given by the debtor if he defaults, so as to cause a loss to the creditor
\end{abstract}

\title{
Keywords: Bank Credit Agreement, SKMHT, Tabanan Regency.
}

\section{Pendahuluan}

\subsection{Latar Belakang}

Pembangunan ekonomi sebagai bagian dari pembangunan nasional merupakan salah satu upaya untuk mewujudkan rakyat yang adil dan makmur. Dalam rangka memelihara kesinambungan pembangunan tersebut, para pelakunya meliputi baik pemerintah maupun masyarakat sebagai orang perseorangan dan badan hukum, sangat memerlukan dana dalam jumlah yang besar. Hal ini berakibat meningkatnya kegiatan pembangunan, meningkat juga keperluan akan tersedianya dana yang sebagian besar diperoleh melalui kegiatan perkreditan $^{1}$.

Kebutuhan akan dana saat ini semakin meningkat, seiring dengan pesatnya perkembangan dunia usaha. Salah satu syarat untuk 
menikmati fasilitas kredit tersebut adalah adanya jaminan, yang digunakan untuk pelunasan. Dalam Pasal 15 Ayat (3) dan (4) UUHT dinyatakan suatu jangka waktu bagi SKMHT untuk hak atas tanah yang sudah terdaftar dan belum terdaftar. ${ }^{1}$ Dalam faktanya sering terjadi kerugian yang dialami debitur akibat ketentuan tersebut, utamanya di Kabupaten Tabanan.

Pelaksanaan SKMHT di Kabupaten Tabanan dalam perjanjian kredit sering mengalami hambatan, terutama mengenai hak atas tanah yang belum terdaftar. Hal itu disebabkan karena jangka waktu proses jual bell pada Kantor BPN sering melebihi batas waktu 3 bulan, sehingga proses untuk mendapatkan APHT melebihi jangka waktu berlakunya SKMHT. Konsekuensinya apabila telah lewat waktu maka SKMHT tersebut akan batal demi hukum, akibatnya kreditur tidak memiliki hak untuk mengeksekusi jaminan yang diberikan debitur bila wanprestasi, dan debitor tidak mendapatkan biaya yang diperlukan dalam usaha bisnisnya. Hal ini dapat menimbulkan kerugian bagi kedua belah pihak.

Hal tersebut dikarenakan lalu lintas kegiatan pengurusan pertanahan termasuk, pendaftaran jual beli, pendaftaran pemasangan Hak Tanggungan dan Iain-lain pada Kantor BPN Kabupaten Tabanan sangat padat, dan disamping itu proses birokrasinya juga rumit sehingga jangka waktu masing-masing proses pengurusan sertipikat tanah sangat lama, daripada kabupaten/kota lainnya khususnya di Provinsi Bali.

Berdasarkan dari pemaparan latar belakang masalah di atas maka penulis tertarik untuk melakukan penelitian tentang bagaimana proses pelaksaan perjanian kredit yang di ikat dengan hak tanggungan,serta bagaimana akibat hukum terlaksananya Surat Kuasa Membebankan Hak Tanggungan (SKMHT) dalam perjanjian kredit bank apabila melewati jangka waktu yang ditentukan. Melalui penelitian dan penulisan karya tulis ilmiah penulis menuangkannya dalam bentuk skripsi dengan judul "PELAKSANAAN PERJANJIAN KREDIT BANK DENGAN SURAT KUASA MEMBEBANKAN HAK TANGGUNGAN (SKMHT) DI KABUPATEN TABANAN."

${ }^{1}$ Maria S.W. Sumardjono, Memahami Prinsip-prinsip UUHT, Kompas, 19 Maret 2004 


\subsection{Rumusan Masalah}

Berdasarkan latar belakang tersebut, adapun rumusan masalah yang akan dibahas sebagai berikut :

1. Bagaimana proses pelaksaan perjanjian kredit yang di ikat dengan SKMHT ?

2. Bagaimana akibat hukum terlaksaanaan surat kuasa membebankan hak tanggungan (SKMHT) dalam perjanjian kredit Bank apabila melewati jangka waktu yang ditentukan.?

\subsection{Tujuan}

Untuk mengetahui proses pelaksaan perjanjian kredit bank yang di ikat dengan hak tanggungan,serta untuk mengetahui akibat hukum terlaksaan perjanjian kredit, Tujuan penulisan jurnal ilmiah ini adalah untuk mengetahui akibat hukum terlaksananya SKMHT dalam perjanjian kredit bank apabila melewati jangka waktu yang ditentukan dan hal yang menjadi kendala dalam pelaksanaan SKMHT dalam perjanjian kredit bank serta bagaimana upaya dalam mengatasinya khususnya di Kabupaten Tabanan.

\section{Isi Makalah}

\subsection{Metode Penelitian}

\subsubsection{Jenis Penelitian}

Metode penelitian yang digunakan dalam menjawab permasalahan yang diangkat yaitu penelitian hukum empiris. penelitian ini menggunakan jenis penelitian hukum empiris yang memiliki sifat atau karakter yang beranjak dari adanya kesenjangan antara das sein dan das so lien yaitu kesenjangan teori dengan kenyataan, atau kesenjangan keadaan teoritis dengan fakta hukum (teori dan fakta tidak sesuai), yaitu adanya kesenjangan antara Pasal 15 Ayat (3) dan (4) UUHT tentang SKMHT dengan fakta-fakta yang terjadi di lapangan. ${ }^{2}$

\subsubsection{Jenis Pendekatan}

Penelitian ini menggunakan pendekatan fakta (The Fact Approach) dan pendekatan perundang-undangan (The Statue Approach). Pendekatan fakta (The Fact Approach) dilakukan dengan melihat keadaan nyata di wilayah penelitian. Pendekatan perundangundangan (The Statue Approach) dilakukan dengan kajian terhadap

\footnotetext{
2 Rinakusniawati, 2003, Konseptualisasi Masalah Penelitian, Bandung, h. 40
} 
undang-undang yang dikaitkan dengan permasalahan yang ada di lapangan. ${ }^{3}$

\subsubsection{Data}

Data yang dipergunakan dalam jurnal ilmiah ini diantaranya yaitu:

1. Data primer merupakan data yang diperoleh langsung dari sumber utama di lapangan, yaitu data yang diperoleh langsung dari sumber pertama di lapangan baik dari responden maupun informan, dimana data tersebut berasal dari observasi atau pengamatan secara langsung ke tempat kejadian dan melalui wawancara. ${ }^{4}$

2. Data Sekunder adalah data yang diperoleh dari tangan kedua atau dengan kata lain data yang bukan berasal dari sumber utama, yang dalam hal ini berasal dari peraturan perundangundangan terkait dengan permasalahan, selain itu juga berasal dari literature-literatur buku, kamus hukum, website, media masa, social media dan lain sebagainya.

\subsubsection{Teknik Pengumpulan Data}

Penyusunan jurnal ilmiah ini menggunakan metode penelitian hukum empiris, maka teknik pengumpulan bahan hukum primer dilakukan dengan teknik wawancara (interview) dan teknik wawancara dilakukan bukan sekedar bertanya kepada seseorang melainkan juga dibarengi dengan pertanyaan-pertanyaan yang diperuntukkan kepada narasumber atau informan, pertanyaan itu dirancang untuk mendapatkan jawaban-jawaban yang relevan dengan masalah penelitian ini, hal tersebut dilakukan agar hasil wawancara nantinya memiliki nilai validitas.. 5

\subsection{Hasil Analisa}

\subsubsection{Proses Pelaksanaan Perjanjian Kredit Yang Di Ikat Dengan SKMHT}

Pasal 15 ayat (1) UUHT dinyatakan bahwa pemberian hak tanggungan wajib dilakukan sendiri oleh pemberi Hak Tanggungan dengan cara hadir dihadapan PPAT. Hanya apabila karena sesuatu sebab tidak dapat hadir sendiri dihadapan PPAT, ia wajib menunjuk pihak lain sebagai kuasanya,dengan SKMHT yang berbentuk akta autentik.Pembuatan SKMHT selain oleh Notaris juga di tugaskan kepada PPAT,karena PPAT ini yang keberadaan nya sampai pada

${ }^{3}$ Peter Mahmud Marzuki, 2011, Penelitian Hukum, Kencana, Jakarta, h. 138

4 Ade Saptomo, 2009, Pokok-Pokok metodologi Penelitian Hukum Empiris Murni, Trisakti, Jakarta, h.81.

5 Soerjono Soekanto, 2015, Pengantar Penelitian Hukum, Cet. 3, Penerbit Universitas Indonesia (UI-Press), Jakarta, h. 69 
wilayah kecamatan dalam rangka pemerataan pelayanan di bidang pertanahan.Dengan demikian,jika notaris berwenang membuat SKMHT untuk tanah-tanah di seluruh wilayah Indonesia,maka PPAT hanya boleh membuat SKMHT untuk tanah-tanah yang berada di dalam wilayah jabantan nya terutama di tempat-tempat yang tidak ada Notaris yang bertugas.Surat kuasa tersebut harus diberikan langsung oleh pemberi hak tanggungan dan wajib memenuhi persyaratan mengenai muatannya sebagai mana di tetapkan dalam pasal 15 Ayat (1) tersebut. Jika SKMHT tidak dibuat sendiri oleh pemberi hak tanggungan atau tidak memenuhi persyaratan tersebut di atas, maka surat kuasa yang bersangkutan batal demi Hukum.artinya surat kuasa itu tidak dapat digunakan sebagai dasar pembuatan APHT.

Berdasarkan hasil wawancara pada beberapa Bank yang ada di kabupaten Tabanan, bahwa penggunanaan SKMHT yang lahir dari perjanjian kredit terjadi karena kreditor yakin pinjamannya akan aman dikarenakan jaminan yang di berikan debitor adalah berupa hak atas tanah yang dipasang SKMHT serta kreditor yakin akan kemampuan debitur dalam mengembalikan kredit sesuai kesepakatan.Lebih lanjut menurut keterangan dia bahwa keuntungan yang diproleh dari penggunaan SKMHT adalah kredit yang di berikan oleh kreditor menjadi lebih terjamin. Kredit tersebut terjamin dikarenakan diberikan nya hak dan kekuasaan kepada bank untuk mendapat pelunasan dari agunan apa bila debitor melakukan cidera janji, yaitu untuk membayar kembali utangnya pada waktu yang telah di tentukan dalam perjanjian,dan adanya kepastian hokum kepada pihak Bank bahwa kreditnya akan tetap kembali dengan cara mengesekusi jaminan kreditnya.

\subsection{2 akibat hukum terlaksaanaan surat kuasa membebankan hak tanggungan (SKMHT) dalam perjanjian kredit Bank apabila melewati jangka waktu yang ditentukan}

Pembuatan SKMHT dibuat guna menjadi jembatan untuk mewujudkan pembuatan APHT di kemudian hari dikaranakan pada saat itu APHT belum dapat dibuat sehingga terpaksa dibuat SKMHT lebih dahulu, missal pada saat pembuatan akta perjanjian kredit seharusnya dilanjutkan dengan pembuatan APHT namun karena sertifikat sedang dalam keadaan proses peralihan hak atau dalam proses proyaan menyebabkan APHT tidak dapat dibuatkan saat itu. Bila kreditur setuju maka saat itu dibuat saja akta perjanjian kredit dan SKMHT sedangkan APHT akan dibuatkan dikemudian hari yaitu 
setelah proses peralihan atau proses peroyaan selesai. Pada saat penandatangan APHT ini pihak pemberi Hak tanggungan tidak perlu hadir kehadapan PPAT karena sudah menunjukan pihak lain sebagai kuasanya untuk mendatangani APHT,kuasa mana adalah SKMHT yang telah di tanda tangani oleh pemberi jaminan pada saat bersamaan ditandatangani nya akta perjanjian kredit. Pada umum nya ditandatangani oleh pihak kreditur,sehingga APHT yang dibuat berdasarkan SKMHT pada umum nya di tanda tangani oleh pihak kreditur yang mewakili pemberi jaminan sebagai pihak kesatu dan pihak kedua yaitu pihak penerima jaminan.

SKMHT memberikan kedudukan yang kuat kepada kreditur karena SKMHT tidak dapat ditarik kembali dan tidak di pergunakan atau telah habis jangka waktunya. Oleh sebab itu kreditur tidak perlu merasa khawatir akan kekuatan SKMHT, yang perlu di perhatikan adalah masa berlakunya SKMHT karena SKMHT akan gugur demi hukum bila masa berlakunya berakhir.

Menurut bapak dan ibu Notari/PPAT di kabupaten Tabanan menyatakan bahwa dimana, dalam pelaksaanya SKMHT yang memiliki jangka waktu 3 bulan (Pasal 15 ayat (4) UUHT) tidak cukup waktu untuk sampai pada tahap pemasangan APHT, dan konsukuensi nya apabila telah lewat waktu maka SKMHT tersebut akan batal demi hukum. Akibatnya kreditur tida memiliki hak untuk mengesekusi jaminan yang di berikan debitur bila wanprestasi, dan debitur tidak mendapatkan biaya dalm usaha bisnis nya.hal ini dapat menimbulkan kerugian kedua belah pihak. Lebih lanjut menurut penjelasan beliau bahwa praktek nya terhadap tanah yang belum bersertifikat/terdaftar, setelah SKMHT ditandatangani maka proses yang menjadi hambatan adalah persertifikatanya. Hal ini dikaranakan proses tersebut memerlukan waktu yang lama (biasanya lebih dari 3 bulan) dan juga biaya yang cukup besar. 


\subsection{3}

Berdasarkan hasil wawancara dengan salah satu pegawai Bank di wilayah Kabupaten Tabanan, penyelesaian secara administrasi perkreditan antara lain sebagai berikut:

1. Penjadwalan kembali (rescheduling), yaitu perubahan syarat kredit yang menyangkut jadwal pembayaran dan atau jangka waktu termasuk masa tenggang, baik meliputi perubahan besarnya angsuran maupun tidak;

2. Persyaratan kembali (reconditioning), yaitu perubahan sebagian atau seluruh syarat-syarat kredit yang tidak terbatas pada perubahan jadwal pembayaran, jangka waktu, dan atau persyaratan lainnya sepanjang tidak menyangkut perubahan maksimum saldo kredit dan konversi seluruh atau sebagian dari pinjaman menjadi penyertaan bank;

3. Penataan kembali (restructuring), yaitu perubahan syarat-syarat kredit berupa penambahan dana bank; dan/atau konversi seluruh atau sebagian tunggakan bunga menjadi pokok kredit baru, dan/atau konversi seluruh atau sebagian dari kredit menjadi penyertaan dalam perusahaan. ${ }^{6}$

Sedangkan, penyelesaian melalui jalur hukum antara lain:

1. Melalui Panitia Urusan Piutang Negara;

2. Melalui badan peradilan;

3. Melalui arbitrase atau Badan Alternatif Penyelesaian Sengketa.

Oleh karena itu, memang barang jaminan dapat dilelang sebelum lewat jangka waktu pembayaran kredit dalam hal debitur melakukan tindakan wanprestasi lainnya. Meski demikian, ada baiknya ditempuh upaya-upaya secara administrasi terlebih dahulu untuk menyelesaikan kredit yang bermasalah sebelum melakukan gugatan ke pengadilan dan mengeksekusi barang jaminan. (Wawancara, 12 November 2018).

\section{Penutup}

\subsection{Simpulan}

1. Proses pembebanan Hak Tanggungan dilaksanakan melalui dua tahap kegiatan yaitu tahap pemberian Hak Tanggungan, yang dilakukan di hadapan Pejabat Pembuat Akta Tanah (PPAT) dan kedua, tahap pendaftaran Hak Tanggungan, yang dilakukan di

6 Subekti dan Johannes Gunawan, 1996, Jaminon-jaminan untuk Pemberian Kredit Termasuk Hak Tanggungan Menurut Hukum Indonesia, PT. Citra Aditya Bakti, Bandung, h.45 
Kantor Pertanahan. Tahap pemberian Hak Tanggungan diawali atau didahului dengan janji untuk meberikan Hak Tanggungan sebagai jaminan pelunasan utang tertentu. Janji untuk memberikan Hak Tanggungan tersebut dituangkan di dalam dan merupakan bagian tak terpisahkan dari perjanjian utang piutang yang bersangkutan atau perjanjian lainnya yang menimbulkan utang tersebut.

2. Akibat hukum dari terlaksa nya SKMHT dalam perjanjian kredit Bank apa bila melebihi jangka waktu yg di tentukan maka SKMHT tersebut batal demi hukum. Akibat nya kreditur tidak memiliki hak untuk mngesekkusi jaminan yang di berikan debitur bila melakukan wanprestasi, senhingga menimbulkan kerugian bagi kreditur.

\subsection{Saran}

Kepada para pihak khususnya kreditor agar mempertimbangan penggunaan SKMHT dalam hal debitor meminjam kredit. Karena perbedaan dari segi fungsi antara SKMHT dan APHT, perbedaann dari segi jangka waktu berlakunya maupun tentang perbedaan kedudukan kreditor pada SKMHT dan APHT. Oleh karena itu kreditor dapat menilai apakah nilai kredit tersebut sesuai bila digunakan SKMHT atau langsung dengan APHT.

\section{Daftar Pustaka}

\section{Buku}

Ade Saptomo, 2009, Pokok-Pokok metodologi Penelitian Hukum Empiris Murni, Trisakti, Jakarta.

Boedi Harsono, 1999, Hukum Agraria Nasional Jilid I, Djembatan, Jakarta.

Peter Mahmud Marzuki, 2011, Penelitian Hukum, Kencana, Jakarta. Rinakusniawati, 2003, Konseptualisasi Masalah Penelitian, Bandung. Soerjono Soekanto, 2015, Pengantar Penelitian Hukum, Cet. 3, Penerbit Universitas Indonesia (UI-Press), Jakarta.

Subekti dan Johannes Gunawan, 1996, Jaminon-jaminan untuk Pemberian Kredit Termasuk Hak Tanggungan Menurut Hukum Indonesia, PT. Citra Aditya Bakti, Bandung.

\section{Artikel}

Maria S.W. Sumardjono, Memahami Prinsip-prinsip UUHT, Kompas, 19 Maret 2004

\section{Peraturan Perundang-Undangan}

Undang-Undang Dasar Negara Republik Indonesia Tahun 1945 
Undang-Undang No. 10 tahun 1998 tentang Perbankan (Lembaran Negara Republik Indonesia Tahun 1998 Nomor 3790)

Undang-Undang No. 5 Tahun 1960 Tentang Peraturan Dasar PokokPokok Agraria (Lembaran Negara Republik Indonesia Tahun 1960 Nomor 2043)

Undang-Undang No.4 Tahun 1996 Tentang Hak Tanggungan Atas Tanah Beserta Benda-Benda Yang Berkaitan Dengan Tanah (Lembaran Negara Republik Indonesia Tahun 1996 Nomor 3632) 